\title{
Fintech world: Forced or voluntary adoption and application of digital technologies
}

\author{
S. Kavediya ${ }^{1^{*}}$, S. Saxena ${ }^{2}$ and N. Joshi ${ }^{3}$ \\ ${ }^{1}$ MES Garware College of Commerce, Pune. \\ ${ }^{2 \& 3}$ Jagan Institute of Management Studies, New Delhi.
}

DOI: http://doi.org/10.52814/PJMA.2021.1108

ARTICLE TYPE: Review paper

ARTICLE HISTORY: Submitted: January 2021, Revisions: March 2021, Accepted: March 2021

HOW TO CITE: Kavediya, S.; Saxena, S. and Joshi, N. (2021). Fintech world: Forced or voluntary adoption and application of digital technologies. Prayukti Journal of Management Applications, Vol. 1, Issue 1, pp. 57-63.

*Corresponding author e-mail: sharmilakavediya8@gmail.com

\begin{abstract}
The word digital is in vogue nowadays. In fact, we are invaded so much with the term digital and technology that ithey have become ubiquitous. In the COVID times, these two words have assumed great importance due to the fact that they have come to stay with us. From schools and colleges to hospital and various institutions the common medium which is driving them is Fintech. In fact today wee cannot think of any domain to exist without Fintech. With the pandemic raging across the globe, it become imperative to assess the research question (a) The adoption and adaptation of Fintech as the medium is forced on the masses or it was voluntary? The study is based on the grounded theory approach, wherein data was collected from respondents who were chosen purposively for this study. The data was collected by the authors through the usage of social media tools such as WhatSapp The sample size that went into this study was 118 though the authors had initially targeted for the sample size of 300..The data was treated by means of applying data mining and predictive techniques and association mining. These provided the ground reality to the objective of seeking answers to the research question. The findings indicate that COVID pandemic has resulted in the voluntary adoption of the Fintech services. However, as India is basically cash based economy there are indications that the finetch services may see the downfall as the masses may revert to dealing in cash transactions. The limitation that surfaced during the study included that the inclusion of controlling, and mediating variables would have significantly provided better findings. On the other hand, small sample size also exposed the limitations of the study as it has impacted the findings. the contribution to the study stems from the fact that the study is conducted in an environment wherein teh entire globe is constrained or forced to operate with restrictions such as limited usage of cash. The limitation of the study is the small sample size and the domain being confined to NCR region and higher educational institutions.
\end{abstract}

KEYWORDS: COVID, Digitalization, Fintech, Grounded Theory. 


\section{INTRODUCTION}

The COVID pandemic, jostled the world. It destructed several established business models, brought about significant transformational changes both at organizational level and at personal level.

\section{LITERATURE REVIEW}

Digital Technology. The words that has mesmerized the world in terms of wonderful services and devices it had benefitted mankind. For, it has demonstrated its ability and potential by gifting Smartphones to remain in close contact with the world; digital watches to keep track of our time and status of our health; digital photo labs to develop movie clippings and digital technology to avail medical services remotely.. But this is not the end, in fact, this digitalization has impacted our financial sector in terms of the coinage of the new word Fintech. The impact if Fintech is clearly is clearly visible in the form of services like getting personal loan without venturing out of our houses.

HWoever, there are negative side to the technological world and this is being demonstrated in teh Fintech services. According to Soewito, Benfano\& M. Isa, Sani. (2015); M. Buerlein (2008); S.Azhar (2011); S.S. Dawes (1996); E. Brynjolfsson (1996) digital technology is poised to impact the social development including the ability of financial decisions of an individual they struggle incessantly to stay connected to digital gadgets. In the same context, Janna Anderson and Lee Rainie(2018) in corroboration concluded in their study that digital technologies have developed into the form of an addictive technologies as they have the power to capture the attention and mind occupancy of the masses and this is alarming as it threatens to impact their psychological well beings (Wildemeersch, Danny; Jütte, Wolfgang, 2017). Hence we are today witnessing the rise of cyber crimes in the form of swindling of finances from the bank and illegal transactions from out bank accounts

However, despite the extensive usage of digital technological services the transformation to digital infrastructure for financial environment is the need of the day and as such, it is required to be implemented in such a manner that the masses do not feel that it is forced or rather they are in a position to adopt and adapt the same in an participative manner.

The process of implementation of digital financial transformation is full of challenges and issues. For, there are individuals who will play a crucial role in adoption and sustainability of Fintech programs. On the other hand, processes will drive the implementation program to ensure that the masses respond to the implementation Fintech services. In other words, the triads comprising of people, process and technology are required to be aligned with the organizational objectives. Further, there is always a danger of implementation program slipping away into digital fatigue the moment, stakeholders feel that there is no value addition

\section{RESEARCH QUESTION}

On the basis of extant literature review and the grounded theory data from the respondents, the following research question was developed

The adoption and adaptation of Fintech as the medium is forced on the masses or it was voluntary?.

\section{RESEARCH METHODOLOGY}

The research methodology adopted in the development of the paper is based on the grounded theory approach by Glasaer, B \& Strauss, A; 1967. The prime reason for deploying the grounded theory approach in the development of the paper is the fact that COVID pandemic has completely put a halt to the business operations. Thus, with the concept of safe distancing and social distancing in place, the only viable option was to use technology as a medium of making financial transactions. The pace with which transactions were happening forced the financial services sector to assess the result of injection of technology in the finance sector. Thus, the authors, brain stormed on deploying grounded theory approach to determine the empathy of the masses. The authors readily availed the services of zoom, 
Google meet, WhatSapp and other social media tools to understand the research problem and to arrive at the conclusion.

In addition to the usage of grounded theory approach, the authors conducted an extant literature review to determine the previous work which had been conducted and the determination of the variables which could be used in this study.

The questionnaire comprised of two parts. While one part captured the demographic details of the participants, the other part captured the responses of the participants. Google Forms was use was in those cases wherein links were sent through emails which were processed through MS Excel software. On the other hand wherein the response were collected through video calls, social media tools the authors downloaded the data by using technological tool Weka, which is data mining tool. Also, the authors, used python programming language to perform the data mining operations. The sampling adopted in the development of the paper was purposive. The reason for deploying purposive sampling is the fact the Fintech is a domain in which the quality of the response is of prime concern. The sample size initially targeted was to the tune of 600 but after verification, validation and codification it was reduced to 538. As multichannel avenues were deployed for data collection, the respondents include pan India demographical domain. The analysis was done on the basis of association rule mining of data analytic techniques.

Once the data was downloaded, the authors went about the coding of the data and to development of the concepts which will lead to the answer to the questions.

The findings, limitations, future recommendations and the conclusion are arrived at on the basis of the research questions.

\section{FINDINGS AND INTERPRETATION}

The collection of the data from the sources led to the formulation of coding stage of the grounded theory approach (Saldana, Johnny, 2009). The following codes or categories were allocated based on the responses to the questions. Table 1 below represents these categories

\begin{tabular}{|c|l|}
\hline $\begin{array}{r}\text { Table 1: Formulation of categories for the responses to the questionnaire collected as a part of the } \\
\text { Fintech program implementation based on grounded theory approach. }\end{array}$ \\
\hline Question \# & \multicolumn{1}{c|}{ Category } \\
\hline 1. & Digital Competency Skill Set for Fintech Services \\
\hline 2. & Digital Competency Programs for Fintech Services \\
\hline 3. & Failure Of Digital Fintech Competency Programs \\
\hline 4. & Mentors Role In Digital Transformation pertaining to Fintech \\
\hline 5. & Fintech Training Programs \\
\hline 6. & Long Term Achievement Of Digital Transformation of Fintech Programs \\
\hline 7. & Detoxification From Digital Devices which hampers Fintech programs \\
\hline 8. & Detachment From Digital Devices which impact Fintech services \\
\hline 9. & Detachments Effects \\
\hline 10. & Analogue Comparison \\
\hline 11. & Usage Of Social Media \\
\hline 12. & Social Media \\
\hline 13. & Negativity Of Digital Connectivity pertaining to Finetch programs \\
\hline 14. & Preparation for Fintech program implementation \\
\hline 15. & Material Research of Fintech programs \\
\hline
\end{tabular}

\section{THE CLUSTER FORMULATION PHASE OF THE RESEARCH PROCESS}

The next phase of the research methodology started with the process of cluster formation so on the basis of similarities of the categories identified in table 1. The cluster formulation is arrived on the basis of grouping together of similarities. This grouping will assist in the Fintech implementation program .a Table 2, below provides the clusters. The methodology was manually on account of the fact that the sample size was small. Had the sample size been large then we would have used algorithms. 


\begin{tabular}{|c|c|}
\hline \multicolumn{2}{|c|}{ Table 2: Formulation of clusters by clubbing the categories } \\
\hline Cluster \# & Clubbed Categories \\
\hline Cluster No. 1 & $\begin{array}{l}\text { Digital Competency Skill Set for Fintech Services } \\
\text { Digital Competency Programs for Fintech Services } \\
\text { Mentors Role In Digital Transformation pertaining to } \\
\text { Fintech } \\
\text { Fintech Training Programs }\end{array}$ \\
\hline Cluster No. 2 & $\begin{array}{l}\text { Long term achievement of digital transformation } \\
\text { Detoxification from digital devices } \\
\text { Detachment from digital devices } \\
\text { Detachment affects }\end{array}$ \\
\hline Cluster No. 3 & $\begin{array}{l}\text { Analogue comparison } \\
\text { Usage of social media } \\
\text { Social media } \\
\text { Negativity of digital connectivity }\end{array}$ \\
\hline Cluster No. 4 & Failure Of Digital Fintech Competency Programs \\
\hline Cluster No. 5 & $\begin{array}{l}\text { Preparation for Fintech program implementation } \\
\text { Material Research of Fintech programs }\end{array}$ \\
\hline
\end{tabular}

From the table 2 it is seen that 5 nos. of clusters were formulated and each cluster contained the categories which were similar in nature. For example, cluster 1 contains those clusters which are related to development of digital Financial literacy a part of implementation program. Cluster 2, contains categories which will provide sustainability to Financial implementation program on long term basis while cluster 3 contains entries which provide the drift towards analogue devices such as excessive usage of social media, negativity of digital connectivity and the social media. On the other hand, cluster 4 is a single category, which acts as a pivot cluster for failure of digital implementation programs which digital competency as the core.

The end of the cluster formulation phase led to the formulation of the metrics part associated to the cluster which includes the determination of cluster centroid. This is number based on the number of transactions or record which have answered affirmatively to the questions under the particular category. The centroid was determined by means of Euclidean distance formula. Table 3 below depicts the centroid of the above-identified 5 clusters.

\begin{tabular}{|c|c|c|}
\hline Cluster-Category & Measured Score & $\begin{array}{l}\text { Centralized } \\
\text { Cluster Score }\end{array}$ \\
\hline \multicolumn{3}{|l|}{ Cluster \#1 } \\
\hline Digital Competency Skill Set for Fintech Services & 23.60 & \\
\hline Digital Competency Programs for Fintech Services & 29.50 & 29.01 \\
\hline Mentors Role In Digital Transformation pertaining to Fintech & 23.60 & \\
\hline Fintech Training Programs & 39.33 & \\
\hline \multicolumn{3}{|l|}{ Cluster \#2 } \\
\hline Long term achievement of digital transformation & 29.50 & \\
\hline Detoxification from digital devices & 29.50 & 27.04 \\
\hline Detachment from digital devices & 19.67 & \\
\hline Detachment affects & 29.50 & \\
\hline \multicolumn{3}{|l|}{ Cluster \#3 } \\
\hline Analogue comparison & 23.60 & \\
\hline Usage of social media & 29.50 & 25.56 \\
\hline Social media & 19.67 & \\
\hline Negativity of digital connectivity & 29.50 & \\
\hline \multicolumn{3}{|l|}{ Cluster \#4 } \\
\hline Failure Of Digital Fintech Competency Programs & 29.50 & 29.50 \\
\hline \multicolumn{3}{|l|}{ Cluster \#5 } \\
\hline Preparation for Fintech program implementation & 39.33 & 39.33 \\
\hline Material Research of Fintech programs & 39.33 & \\
\hline
\end{tabular}


On the basis of the centralized cluster score, we determine the process of determining the proximity of these clusters with one another. By using Euclidean distance formula, table 4 depicts the proximity of the clusters.

\begin{tabular}{|c|c|c|}
\hline \multicolumn{3}{|c|}{$\begin{array}{l}\text { Table 4: showing the minimum distance between the clusters. }{ }^{6 *} \text { ' Cluster } \# 5 \text { has been } \\
\text { deliberately left out for analysis }\end{array}$} \\
\hline Cluster Proximity between clusters & Euclidean distance & Minimum distance \\
\hline Between 1 \& 4 & 0.49 & \multirow{9}{*}{0.49} \\
\hline Between $2 \& 4$ & 2.46 & \\
\hline Between 3 \& 4 & 3.93 & \\
\hline Between 4 \& 4 & 0.00 & \\
\hline Between 5 \& 4 & 9.83 & \\
\hline Between 2 \& 3 & 1.48 & \\
\hline Between $2 \& 5$ & 12.29 & \\
\hline Between $3 \& 4$ & 13.77 & \\
\hline$*$ Between 3 \& 5 & 13.77 & \\
\hline
\end{tabular}

From table 4, it is evident that the clusters $1,2,3 \& 4$ are the key clusters playing a crucial role in the success and failure of the digitalization Fintech implementation programs. This is reflected as the centroid distance between success (cluster 1,2 and 3) and failure (cluster 4) is minimum amongst the other cluster members.

Table 5 below depicts the results that Fintech digital programs have the highest support of $64 \%$ of the respondents with the confidence level of $79 \%$. This indicates that competency processes must form a core process. In other words constant attention and support of management in terms, resources and other necessities must be provided. In a same manner the Fintech training programs have the support of $43 \%$ with the confidence of $77 \%$. In a similar manner, we can interpret other factors and subsequently decide their importance for the formulation of processes.

\begin{tabular}{|l|c|c|}
\hline \multicolumn{1}{|c|}{$\begin{array}{c}\text { Table 5: Application of association mining methodology to determine the possible strategy and } \\
\text { plan of action for Fintech digitalization program }\end{array}$} \\
\hline \multicolumn{1}{|c|}{ Support } & Confidence \\
\hline Digital Competency Skill Set for Fintech Services & 0.64 & 0.79 \\
\hline Digital Competency Programs for Fintech Services & 0.43 & 0.77 \\
\hline $\begin{array}{l}\text { Mentors Role In Digital Transformation pertaining to } \\
\text { Fintech }\end{array}$ & 0.35 & 0.56 \\
\hline Fintech Training Programs & 0.35 & 0.52 \\
\hline Long term achievement of digital transformation & 0.31 & 0.55 \\
\hline Detoxification from digital devices & 0.29 & 0.47 \\
\hline Detachment from digital devices & 0.29 & 0.35 \\
\hline Detachment affects & 0.26 & 0.55 \\
\hline Analogue comparison & 0.25 & 0.39 \\
\hline Usage of social media & 0.24 & 0.35 \\
\hline Social media & 0.19 & 0.36 \\
\hline Negativity of digital connectivity & 0.18 & 0.25 \\
\hline Failure Of Digital Fintech Competency Programs & 0.17 & 0.29 \\
\hline
\end{tabular}

Table 5 is generated to get the feel of the key parameters which will form the core processes when no association rule is specified. In other words, simply by providing more thrust to digital competency programs the respondents believe that $64 \%$ of the digitalization can be achieved. However, Finetch digitalalization transformation program does not function alone; it must have antecedents and consequents. In other words, it is the inter linking of various processes which lead to success. 
Table 6 and table 7 does just that by following the association rule mining based on antecedent and consequent. The concept is based on developing rules and then determining the baseline confidence, rule based support, the confidence support and the lift. Lift provides predicts the chances of the defined rule to be true. For example, the rule 1 which has the antecedent of top management support and the consequent of mismatch between expectations has the lift factor of 3.03. This indicates that there are 3.03 times of happening of mismatch of expectations even when there is support of government. In a similar manner, for rule 3, which has the lift factor of 5.62 indicates digital failure and fatigue is likely to happen to the tune of 5.6 times when the respondent is tired and there is a tendency to drift to old style of work.

\begin{tabular}{|c|l|}
\hline \multicolumn{2}{|l|}{$\begin{array}{l}\text { Table 6: Depicting the rules of the consequent and the antecedent for association mechanism } \\
\text { deployment }\end{array}$} \\
\hline Rule \# & \multicolumn{1}{c|}{ Antecedent \& Consequent } \\
\hline 1 & $\begin{array}{l}\text { By ensuring that government and top management sets an example of digital Fintech } \\
\text { transformation by drafting policies and procedures which are aligned with objectives of } \\
\text { digitalization \& there is always a mismatch between what we want, what the government and } \\
\text { management wants and what the output should be in the }\end{array}$ \\
\hline 2 & $\begin{array}{l}\text { When the masses are constantly invaded by various messages and emails from social media sites } \\
\text { and others and they are required to complete financial transactions on urgent basis and important } \\
\text { task hence this is the time they feel the need to Detox \& there is always a mismatch between } \\
\text { what they want, what the management wants and what the output should be in the given context }\end{array}$ \\
\hline 3 & $\begin{array}{l}\text { When an individual is tired and about to go to sleep and these messages, calls, SMS and other } \\
\text { irritants are constantly announcing their arrival \& due to work pressure and inadequate skills for } \\
\text { digital work, stakeholders resort to their old style of work }\end{array}$ \\
\hline 4 & $\begin{array}{l}\text { Types of activities in which individual is uninterested such as copy and pasting from net and } \\
\text { transferring it to spreadsheet program and have been doing it for long period of time \& there is } \\
\text { always a mismatch between what he wants and what the management wants and what the output } \\
\text { should be in the given context }\end{array}$ \\
\hline 5 & $\begin{array}{l}\text { It helps you in the process of looking at the things in an objective manner clearly and think in } \\
\text { various aspects \& there is always a mismatch between what we want, what the management } \\
\text { wants and what the output should be in the given context }\end{array}$ \\
\hline 6 & $\begin{array}{l}\text { When an individual goes financial training programs instead of e-book available in the internet \& } \\
\text { due to work pressure and inadequate skills for digital work, stakeholders resort to their old style } \\
\text { of work }\end{array}$ \\
\hline $\begin{array}{l}\text { Generating multiple versions of fintech services and products c and thus leading to confusion \& } \\
\text { there is always a mismatch between what an individual want, what the management wants and } \\
\text { what the output should be in the given context }\end{array}$ \\
\hline
\end{tabular}

Table 7: Depicting the Baseline Support, Rule based support, Confidence based support and Lift for the defined rules

\begin{tabular}{|c|c|c|c|c|}
\hline Rule \# & $\begin{array}{c}\text { Baseline } \\
\text { confidence (\%) }\end{array}$ & $\begin{array}{c}\text { Rule based } \\
\text { Support (\%) }\end{array}$ & $\begin{array}{c}\text { Confidence } \\
\text { Support (\%) }\end{array}$ & Lift \\
\hline 1 & 33.05 & 26.2 & 79.27 & 3.03 \\
\hline 2 & 33.05 & 33.05 & 100 & 3.03 \\
\hline 3 & 17.79 & 14.40 & 80.94 & 5.62 \\
\hline 4 & 33.05 & 16.10 & 48.71 & 3.03 \\
\hline 5 & 33.05 & 27.11 & 82.02 & 3.03 \\
\hline 6 & 17.79 & 16.94 & 95.22 & 5.62 \\
\hline 7 & 33.05 & 22.88 & 69.22 & 3.03 \\
\hline
\end{tabular}

\section{LIMITATIONS}

During the conduct of the study, the limitation that surfaced, included the aspects of inclusion of more variables in the form of controlling variable and mediating variable which could significantly impact the findings. On the other hand, the inclusion of other rules for the basis of association rule mining would have provided better results which can be deployed to assess the research question . 


\section{CONTRIBUTION TO EXISTING LITERATURE REVIEW}

The study contributes to the existing literature in the form of deploying data mining operations for the during the phenomenon which had global impact and has severely impacted the movement of the masses. This has resulted in Fintech services playing a major role in the commercial operations

\section{FUTURE RECOMMENDATION}

The future implications of the study is the fact new variables which have surfaced during the study lead to another direction of research. For example, the inclusion of the variables comprising of students pursuing higher education with finance as elective and having technical degree, how they perceive the role of Fintech when things get back to normal.

\section{CONCLUSION}

The conclusion arrived from the study is the fact that COVID pandemic has voluntarily led to the adoption of digital technologies in the financial domain. However, in the context of Indian scenario, wherein the basic is cash based economy, things may revert other forms of payments and transaction such as cash or possibly in terms of crypto currency.

\section{REFERENCES}

- Anderson, J., \& Raine, L. (2018). 3. Concerns about the future of people's well-being. Pew Research Center.

- Azhar, S. (2011). Building information modeling (BIM): Trends, benefits, risks, and challenges for the AEC industry. Leadership and management in engineering, 11(3), 241-252.

- Bauerlein, M., \& Walesh, S. G. (2009). The Dumbest Generation-How the Digital Age Stupefies Young Americans and Jeopardizes Our Future: . Jeremy P. Tarcher/Penguin, New York, 2008; 978-1-58542-639-3 (Vol. 9, No. 2, pp. 100-100). American Society of Civil Engineers.

- Bhide, Shilpa Vasant (2019). Factors influencing the Use of E-wallets and its Limitations. MERC Global's International Journal of Management. Vol. 7, Issue 3, pp. 222-227.

- Brynjolfsson, E., \& Yang, S. (1996). Information technology and productivity: a review of the literature. Advances in computers, 43, 179-214.

- Chun, T. Y., Birks, M. and Francis, K., 2019. Grounded theory research: A design framework for novice researchers.

- Dawes, S. S. (1996). Interagency information sharing: Expected benefits, manageable risks. Journal of policy analysis and management, 15(3), 377-394.

- Glaser, B., \& Strauss, A. (1967). The discovery of grounded theory: strategies for qualitative research. EE. UU.

- Saldaña, J. (2009). First cycle coding methods. The coding manual for qualitative researchers, 45-145.

- Soewito, B., \& Isa, S. M. (2015). Digital technology: the effect of connected world to computer ethic and family. CommIT (Communication and Information Technology) Journal, 9(1), 23-28.

- Wildemeersch, D., \& Jütte, W. (2017). digital the new normal-multiple challenges for the education and learning of adults. European journal for Research on the Education and Learning of Adults, 8(1), 7-20. 